\title{
Impact of ventricular arrhythmias on survival in patients after myocardial infarction
}

\author{
Katarzyna Mitręga ${ }^{1}$, Agnieszka Kolczyńska ${ }^{2}$, Joanna Hanzel ${ }^{2}$, Sylwia Cebula ${ }^{2}$, Stanisław \\ Morawski $^{2}$, Grzegorz Mencel², Jacek Kowalczyk², Zbigniew Kalarus², Beata Średniawa ${ }^{2}$ \\ Department of Cardiology, Congenital Heart Diseases, and Electrotherapy Silesian Medical University, Silesian Center of \\ Heart Diseases, Zabrze, Poland \\ Correspondence: Katarzyna Mitręga. Address: Department of Cardiology, Congenital Heart Diseases, and \\ Electrotherapy Silesian Medical University, Silesian Center of Heart Diseases, Zabrze, Poland. Email: kas-k2@o2.pl \\ Received: January 5, 2014 \\ Accepted: February 24, 2014 \\ Online Published: February 28, 2014 \\ DOI: $10.5430 /$ ijdi.v1n1p21 \\ URL: http://dx.doi.org/10.5430/ijdi.v1n1p21
}

\section{Abstract}

Introduction: Despite the continuous development of new methods of pharmacological and invasive treatment for patients with acute myocardial infarction (MI) the prognosis of long-term survival is still uncertain. Therefore, there is still need to look for new noninvasive predictors of death in patients after MI.

Aim: To analyze the prognostic value of ventricular arrhythmias in predicting mortality following MI in long-term follow-up.

Methods: We analyzed 390 consecutive patients (114 females and 276 males, aged 63.9 \pm 11.15 years, mean EF: $43.8 \pm$ 7.9\%) with MI treated invasively. On the 5th day after MI 24-hour digital Holter recording was performed to assess the number of premature ventricular beats (VPB) and their sustained forms such as: salvos and nonsustained ventricular tachycardia (nsVT $<30 \mathrm{~s}$ ). The large numbers of ventricular extrasystoles: $\geq 10 \mathrm{VPB} /$ hour were considered as abnormal. In echocardiography the size of heart cavities and cardiac contractile function were evaluated. Within $30.1 \pm 15.1$ months of follow-up 38 patients died.

Results: In the group of patients with MI the mean value of ventricular ectopy during the day was: $318.8 \pm 1447.6$. Large numbers of ventricular extrasystoles were observed in $75 \%$ patients, while nsVT in $6 \%$ patients. Significant differences in the incidence of death after MI were observed in patients with nsVT and ventricular salvos. In the group of patients who died in comparison to the group of patients who survived in long-term follow-up, a significantly less ventricular ectopic incidence was noted $(9.83 \%$ vs $90.17 \%, p<0.01)$. In patients who died after MI more premature ventricular beats $(\geq 10 \mathrm{VPB} / \mathrm{h}$ ) and a greater nsVT incidence were observed; however not significant. Moreover, in patients with MI the systolic and diastolic LV dimension, decreased values of hemoglobin, salvos and nsVT incidence are the independent risk factors of death. The strongest independent risk factor of death after MI is salvos (HR: 1.32, $P<0.01$ ).

Conclusions: In long term follow-up the largest differences in death were observed in patients with ventricular salvos and nsVT. Furthermore, ventricular salvos are the strongest independent risk factor of death in patients with AMI.

\section{Keywords}

Myocardial infarction, Ventricular arrhythmias, Salvos 


\section{Introduction}

Cardiovascular diseases, because of their widespread occurrence in Poland and worldwide, remain a serious social, medical and economic problem. It is estimated that acute coronary syndrome (ACS) in the Polish population affects about 250000 cases annually, and the incidence of myocardial infarction (MI), both with ST-segment elevation (STEMI) or non-ST elevation (NSTEMI) affects about 100000 people every year ${ }^{[1]}$. In $50 \%$ of these cases it is the first symptom of coronary artery disease, and despite significant diagnostic and treatment progress, one year mortality is still above

$40 \%{ }^{[2,3]}$. Abnormal heart rhythm can occur as early or late complications of acute myocardial infarction, however most of them are accompanied by acute phase of ACS. The mechanism of heart rate disorders is mainly based on the generation and conduction of abnormal impulses, increased or released heart automatism and the emergence of reentry rhythm ${ }^{[4]}$. Additionally, increased secretion of catecholamine during the ACS might play a significant role in the enhancing ischemia ${ }^{[5]}$. The main complication of ACS is heart failure which is a result of prolonged hypoxia and necrosis of cardiac muscle and has been proven as an independent predictive factor for ventricular arrhythmias caused by electrical instability of heart muscle ${ }^{[4,6]}$. These ventricular arrhythmias: ventricular tachycardia (VT) and ventricular fibrillation (VF) significantly increase the risk of sudden cardiac death (SCD) in the population after myocardial infarction and they represent a group of life-threatening late complications after $\mathrm{MI}^{[7]}$. That is why the aim of the study was to assess the prognostic value of ventricular arrhythmias for long-term total mortality prediction after myocardial infarction.

\section{Material and methods}

We analyzed 309 consecutive patients (276 male, mean age $61.4 \pm 11.2$ years) with acute MI treated with percutaneous coronary intervention (PCI) on admission to the hospital. The inclusion criteria were as follows: a clinically, electrocardiographic and laboratory confirmed myocardial infarction, invasive treatment of acute MI, alive status on the $5^{\text {th }}$ day after acute MI. Patients aged $\geq 80$ years, who died before prior to 24 hour Holter monitoring, with extreme heart failure lasting more than 5 days after myocardial infarction despite the implementation of optimal medical therapy, who required continuous atrio-ventricular pacing, with atrial fibrillation (sustained or paroxysmal), or with other non-sinus rhythms that persisted to the end-hospital rehabilitation were excluded from the study.

Based on clinical examination, medical history and additional testing (i.e., ECG, echocardiography, laboratory tests including the level of glucose, creatinine, hemoglobin and elevated biomarkers of myocardial necrosis such as troponin and/or creatine phosphokinase-MB isoenzyme) the patients were treated invasively on admission.

In accordance with current guidelines, at the time of diagnosis of ACS patients received (prior to, or immediately upon admission) treatment such as dual oral antiplatelet therapy in the form of acetylsalicylic acid loading dose (150-325 $\mathrm{mg}$ ) and clopidogrel (300-600 mg) and intravenous anticoagulation therapy (unfractionated heparin bolus dose of $100 \mathrm{U} / \mathrm{kg}$ body weight). 24-hour Holter monitoring, echocardiography and control biochemical test were performed on average in the fifth day of hospitalization.

\subsection{Holter ECG monitoring}

On the $5^{\text {th }}$ day after MI the 24-hour digital Holter recordings were carried out with the use of Pathfinder 700 Spacelabs Healthcare to assess the number of ventricular arrhythmias, including the number of ventricular premature beats (VPB) and their different patterns /complex forms (salvos, non-sustained ventricular tachycardia / nsVT /). The numerous occurrences of ventricular extrasystoles (VE) were defined as the $\geq 10 \mathrm{VE} /$ hour. Salvos were defined as additional stimulation of 3-5 QRS (> $120 \mathrm{~ms}$ ) in a row. Non-sustained ventricular tachycardia (nsVT) was respectively defined as an episode of ventricular tachycardia that lasts for less than 30 seconds and consisted of six or more consecutive wide duration QRS complexes with the rate $>100 / \mathrm{min}$. 


\subsection{Echocardiography}

Left ventricular dysfunction was evaluated using echocardiography test based on ejection fraction (EF), left ventricular end-systolic diameter (LVESd) and left ventricular end-diastolic diameter (LVEDd). Normal range for the determined parameters was defined as follows: $\mathrm{EF} \geq 55 \%$, LVESd 35-57 mm, LVEDd 30-39 mm.

\subsection{Statistical procedures}

Results are expressed as mean \pm SD. Multivariate Cox regression model was used to evaluate survival analysis, while the qualitative data analysis was performed using $\chi^{2}$ test as modified by Pearson and is shown as percentages. In all cases, differences were considered significant if $P<0.05$.

\subsection{Long-term follow-up}

The mean follow-up of patients enrolled into this study was $30.1 \pm 15.1$ months. The incidence of the following endpoints was death due to any cause defined as total mortality.

Total mortality was $9.38 \%$ (38 patients).

\subsection{Group characteristics}

In the analyzed population 315 patients (81\%) were referred for invasive treatment due to NSTEMI and 75 patients $(19 \%)$ due to STEMI. Based on medical history, reinfarction was confirmed in 80 cases $(20 \%)$ and in $102(26 \%)$ cases of previous diabetes mellitus (DM) were found. In echocardiography the mean left ventricle ejection fraction (EF) was $43.88 \pm 7.70 \%$, and the average sizes of left ventricular end-systolic and end-diastolic volumes were respectively: LVESD $35.22 \pm 9.42$ $\mathrm{mm}$ and LVEDd $51.71 \pm 10.45 \mathrm{~mm}$ (see Table 1). Based on biochemical tests an impaired renal function (GFR $<60$ $\left.\mathrm{mL} / \mathrm{min} / 1.73 \mathrm{~m}^{2}\right)$ was found in $16 \%$ of patients $(\mathrm{n}=62)$ (see Table 2). The comparison of medical and invasive treatment in patients who survived and died after MI was present in Table 3.

Table 1. Demographic and clinical characteristics

\begin{tabular}{ll}
\hline & n (\%) or means \pm SD \\
\hline Age [years] & $61.4 \pm 11.2$ \\
Male gender & $276(70.77 \%)$ \\
LVEF in the fifth day & $43.88 \pm 7.70$ \\
STEMI & $315(80.77 \%)$ \\
NSTEMI & $75(19.23 \%)$ \\
Previous AMI & $80(20.51 \%)$ \\
DM type 2 diagnosed prior to the admission & $102(26.15 \%)$ \\
DM de novo & $16(4.10 \%)$ \\
Follow-up [months] & $30.1 \pm 15.1$ \\
\hline
\end{tabular}

Note. LVEF=left ventricular ejection fraction; STEMI=ST segment elevation myocardial infarction; NSTEMI=non-ST segment elevation myocardial infarction; DM=diabetes mellitus;

Table 2. Biochemical parameters

\begin{tabular}{ll}
\hline & mean \pm SD or n (\%patients) \\
\hline Glucose $[\mathrm{mmol} / \mathrm{l}]$ & $8.4 \pm 3.5$ \\
GFR $<60 \mathrm{ml} / \mathrm{min} / 1.73 \mathrm{~m}^{2}$ & $62(16 \%)$ \\
Creatinine $[\mu \mathrm{mol} / \mathrm{l}]$ & $88.54 \pm 44.18$ \\
Hemoglobin $[\mathrm{mmol} / \mathrm{L}]$ & $9.1 \pm 5.4$ \\
$\left.\mathrm{CK}-\mathrm{MB}_{\max }[\mathrm{ng} / \mathrm{ml}]\right)$ & $187.35 \pm 152.13$ \\
\hline
\end{tabular}

Note. $\mathrm{GFR}=$ glomerular filtration; $\mathrm{CK}-\mathrm{MB}=$ creatine phosphokinase-MB isoenzyme; 
Table 3. Medical and invasive treatment in patients who survived and died after MI

\begin{tabular}{lll}
\hline & $\begin{array}{l}\text { Patients who survived } \\
\mathbf{n}(\boldsymbol{\%})\end{array}$ & $\begin{array}{l}\text { Patients who died } \\
\mathbf{n}(\%)\end{array}$ \\
\hline$\beta$-adrenolytic & $300(85 \%)$ & $30(79 \%)$ \\
ASA & $350(99 \%)$ & $38(100 \%)$ \\
$\mathrm{P}_{2} \mathrm{Y}_{12}$ inhibitor & $352(100 \%)$ & $38(100 \%)$ \\
ACE-I & $280(80 \%)$ & $29(76 \%)$ \\
Statin & $301(85 \%)$ & $35(92 \%)$ \\
PCI & $300(85 \%)$ & $30(79 \%)$ \\
TIMI $<3$ & $41(11 \%)$ & $8(21 \%)$ \\
\hline
\end{tabular}

Note . ASA = aminoacetylosalicylic acid; ACE- $\mathrm{I}=$ angiotensin converting enzyme inhibitor; $\mathrm{PCI}=$ percutaneous coronary intervention; $\mathrm{TIMI}=$

thrombosis in myocardial infarction;

\section{Results}

In 292 patients (75\%) numerous ventricular extrasystoles (VE) were found and the mean value of the occurrence of ventricular ectopy during 24-hour Holter monitoring was $318.38 \pm 1447.6 / \mathrm{h}$ in the entire study group. In long-term follow-up total mortality in the entire population was $9.38 \%(\mathrm{n}=38)$. The patients who died had significantly more VPB occurrence during 24-hour Holter registration than the patients who survived $(90.17 \%$ vs. 9.83\% respectively; $p<0.01)$. Moreover, the non-surviving group of patients had more VPB ( $\geq 10 \mathrm{VPB} / \mathrm{h})$ and increased number of nsVT than the surviving patients.

The multivariate analysis revealed increased LVESd and LVEDd, decreased hemoglobin level, salvos, VPB and nsVT to be independent risk factors for death in patients after MI (see Table 4). The strongest factor was ventricular salvos which increased death risk 1.32-fold. Moreover, the lack of nsVT during Holter recording decreased the mortality by $81 \%$ (see Table 3). The survival probability for patients with or without salvos was present in Figure 1 . What is more, in diabetic patients a significantly higher occurrence of numerous ventricular extrasystoles $(p=0.002)$ was found. Similarly, in patients with impaired renal function $\left(\mathrm{GFR}<60 \mathrm{ml} / \mathrm{min} / 1.73 \mathrm{~m}^{2}\right)$ the occurrence of ventricular ectopic beats was observed significantly more frequently $(p=0.02)$ (see Table 5$)$.

Table 4. Independent risk factors of death in patients after MI

\begin{tabular}{lccc}
\hline & Hazard ratio-HR & $\mathbf{9 5 \%}$ CI & P \\
\hline LVDd & 0.92 & $0.86-0.98$ & $<0.01$ \\
LVSd & 1.09 & $1.01-1.18$ & $<0.05$ \\
$\mathrm{Hb}$ & 1.04 & $1.01-1.06$ & $<0.05$ \\
nsVT (absence) & 0.19 & $0.06-0.65$ & $<0.01$ \\
Salvos (presence) & 1.32 & $1.16-1.49$ & $<0.01$ \\
\hline
\end{tabular}

Note. $\mathrm{LVDd}=$ left ventricular end diastolic diameter; LVSd=left ventricular end systolic diameter; $\mathrm{Hb}=$ hemoglobin; nsVT= non-sustained ventricular tachycardia;

Table 5. Numerous ventricular premature beats (VPB) in patients with diabetes mellitus (DM) type 2 and impaired renal function

\begin{tabular}{lll}
\hline & VPB $\geq \mathbf{1 0} / \mathbf{h}[\%$ patients $]$ & $\boldsymbol{P}$ \\
\hline DM total & 34.13 & 0.002 \\
DM de novo & 17.06 & 0.040 \\
GFR $<60 \mathrm{ml} / \mathrm{min} / 1.73 \mathrm{~m}^{2}$ & 17.35 & 0.020 \\
\hline
\end{tabular}

Note. DM=diabetes mellitus; GFR=glomerular filtration; 


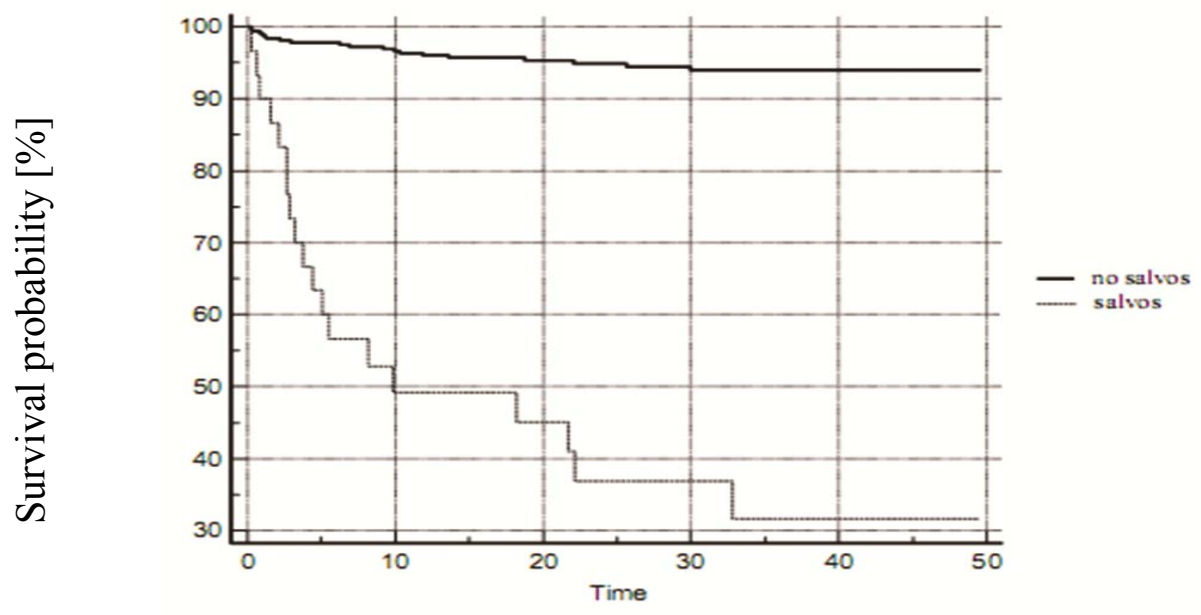

Figure 1. Survival probability in patients with or without salvos.

\section{Discussion}

The results achieved in present study confirmed that cardiac arrhythmias are a frequent complication in patients after myocardial infarction. Ventricular arrhythmias were observed in $75 \%$ of examined patients and it was shown that they constitute an adverse prognostic mortality factor after MI in long-term observation, what was already noticed by Gąsior M. et al. ${ }^{[8]}$. It seems that nsVT deserve particular attention, as their appearance in Holter monitor records is regarded as an adverse prognostic factor, increasing the probability of a SCD particularly if appearing within the first $48 \mathrm{~h}$ after MI ${ }^{[9,10]}$. Based on current study it was shown that the appearance of nsVT in $6 \%$ of patients constituted a serious disadvantageous prognostic factor for SCD after MI. Moreover, the study has shown that the enlargement of the left ventricular end-systolic diameter also significantly increase the risk of death after MI, what confirmed previously observations published by others ${ }^{[11,12]}$. It is commonly known that left ventricular dysfunction is an extremely frequent clinical problem in patients after MI, particularly in patients with long-term ischaemia. Further, it might resulting in activation of many processes within its cells what leads to disadvantageous reconstruction of the left ventricle (remodeling) and impairment of its systolic function. Consequently, it might provide to cardiac failure development with low ejection fraction $(<40 \%)$, which constitutes a disadvantageous prognostic determinant of periinfarction as well as postinfarction period ${ }^{[1,4,13]}$. The another very important issue are all kinds of disorders developing in the course of diabetes e.g. improperly controlled blood glucose level, insulin resistance, obesity, nephropathy or arterial hypertension. All this mentioned above dysfunction significantly increase the risk of life-threatening complications particularly in the group of patients after MI. The outcomes achieved from present analysis clearly indicate that the increased glucose level at admission significantly increases the frequency of numerous ventricular extrasystoles in those patients. It has been proved by earlier researches, that hyperglycaemia was not only triggering adverse hemodynamic effects such as increasing heart rate, systolic and diastolic arterial pressure or catecholamines concentration in blood serum, but also leads to electrophysiological disorders, including the extending QT interval ${ }^{[14]}$. What is more, in the case of the patients with history of diabetes and coronary disease the risk of death grows significantly. Particular attention should be paid on fact that patients with type 2 diabetes have a statistically higher number of additional ventricular excitements as compared with patients without diabetes, what significantly influence on their worsen prognosis for survival as well as the possible complications after the experienced MI. It was proved that patients with type 2 diabetes have an even 2- to 6-fold higher risk of death due to cardiovascular causes as compared to people without diabetes ${ }^{[15]}$. It is probably the result of significantly faster atherosclerosis Published by Sciedu Press 
development in patients with hyperglycaemia. It was previously proved that the control of blood glucose level plays a key part in long-term prognosis with respect to adverse cardiovascular incidents, and each decrease of the glycated haemoglobin level (HbA1c) by 1\% lowers the risk of both serious complications and death associated with DM by $21 \%{ }^{[16]}$. Another essential independent factors worsening the prognosis in patients after MI are both: acute and chronic kidney disease ${ }^{[17]}$. In the case of these patients a significantly greater risk of future adverse cardiovascular incidents has been noticed in comparison with the group of people without kidney disorders ${ }^{[18,19]}$. The consequences of chronic kidney dysfunction are e.g. increased development of atherosclerosis, left ventricle hypertrophy or cardiac failure. Furthermore, it was proved that the increased concentration of creatinine in blood serum is connected with $40 \%$ increase in the risk of cardiovascular incident or death in case of such patients ${ }^{[15]}$. It has also been confirmed by D'Amico M. et al., who proved that the lowering of GFR value $<60 \mathrm{ml} / \mathrm{min} / 1.73 \mathrm{~m}^{2}$ is connected with the greater risk of SCD, furthermore this risk increase proportionally to the further decrease of GFR value ${ }^{[14]}$. Irrespectively of the current studies, the results achieved in the present analysis indicate that in patients with increased creatinine value who suffered from myocardial infarction, additional ventricular excitement is observed significantly more frequently, what might worsening the prognosis in long-term observation. Another problem are low $\mathrm{Hb}$ values or a significant decrease of $\mathrm{Hb}$ value during hospitalization what can also constitute a significant adverse SCD prognostic factor in patients after MI, therefore it is very important to monitor peripheral blood morphology in this group of patients and if necessary to provide appropriate supplementation. This is justified by the significantly reduced oxygen supply into the cells of the cardiac muscle, what leads to damaging cardiac tissue. It is a consequence of long-term or sudden cardiac ischemia and may contribute to compensative activation of the sympathetic nervous system, catecholamine surge and increase heart rate. Moreover, the decreased level of $\mathrm{Hb}$ stimulates the mechanism of disadvantageous remodeling of cardiac muscle which leads to hypertrophy of the left ventricle, and in the end leads to cardiac failure development ${ }^{[20]}$. The importance of this problem is also signified by the fact that it was included amongst others in the ESC guidelines of 2012 (European Society of Cardiology) and included in the new definition of myocardial infarction ${ }^{[21]}$.

To conclude, in clinical practice particular attention should be paid on patients who develop ventricular salvos and nsVTs in the Holter monitor record on average in the 5th day after myocardial infarction, as salvos presence and nsVT absence constitute an independent death risk factor in long-term observation. Since Holter monitoring is commonly accessible in clinical practice this simple risk factors of death after MI can be easy and widely implemented in the routine assessment of patients after MI. Furthermore, a strong emphasize should be put on correct compensation of glucose parameters in patients with already diagnosed type 2 diabetes, as well on the proper treatment and monitoring of patients with nephropathy and anaemia, because these groups of patients are significantly more prone to adverse cardiovascular occurrences in long-term observation after myocardial infarction as compared to the group of people without such disorders.

\section{References}

[1] Opolski G, Filipiak JK. Epidemiology of acute coronary syndromes. Poland (Wroclaw). Urban \& Partner Publisher; 2002.

[2] Granger CB, Goldberg RJ, Dabbous OH, Pieper KS, Eagle KA, Cannon CP. Global Registry of Acute Coronary Events Investigators: Predictors of hospital mortality in the global registry of acute coronary events. Arch Intern Med. 2003; 163: $2345-53$. http://dx.doi.org/10.1001/archinte.163.19.2345

[3] Machete T, Malacrida R, Pasotti E. Epidemiologic variables and outcome of 1972 young patients with acute myocardial infarction. Data from the GISSI-2 database. The GISSI investigators. Arch Int Med. 1997; 157: 865-86. http://dx.doi.org/10.1001/archinte.1997.00440290049005

[4] Khan MG. Heart Diseases. Diagnosis and theraphy. Poland (Wroclaw). Urban \& Partner publishers; 2000.

[5] Ellison KE, Stevenson WG, Sweeney MO, Epstein LM, Maisel WH. Management of arrhythmias in heart failure. Congest Heart Fail. 2003; 9: 91-9. http://dx.doi.org/10.1111/j.1527-5299.2003.00271.x

[6] Kupersmith J, Deedwania PC. Heart's diseases pharmacotherapy. Poland (Wroclaw). Urban\& Partner Publishers; 1998.

[7] Wyman MG, Wyman RM, Criley JM, Cannom DS. Primary ventricular fibrillation cannot be buried; it never died. Am J Coll Cardiol. 2005; 95: 817-8. http://dx.doi.org/10.1016/j.amjcard.2004.12.005 
[8] Gąsior M, Hawranek M, Poloński L. Handbook of Cardiology - doctors and students to the doctors and students. Poland (Kraków). Medycyna Praktyczna Publisher; 2008.

[9] Katritsis DG, Zareba W, Camm AJ. Nonsustained ventricular tachycardia. Am J Coll Cardiol. 2012; 60: $1993-2004$. http://dx.doi.org/10.1016/j.jacc.2011.12.063

[10] KatoT, Yamashit Ta, Sagara K, Linuma H, Fu HT. Progressiv neature of paroxysmal atrial fibrillation. Observations from a 14-yearfollow-up study. Circ J. 2004; 68: 568-72. http://dx.doi.org/10.1253/circj.68.568

[11] Carrabba N, Valenti R, Parodi G, Santoro GM, Antoniucci D. Left ventricular remodeling and heart failure in diabetic patients treated with primary angioplasty for acute myocardial infarction. Circulation. 2004; 110: 1974-9. http://dx.doi.org/10.1161/01.CIR.0000143376.64970.4A

[12] Bolognese L, Neskovic AN, Parodi G, Cerisano G, Buonamici P, Santoro GM et al. Left ventricular remodeling after primary coronary angioplasty. Patterns of left ventricular dilation and long term prognostic implications. Circulation. 2002; 106: $2351-7$. http://dx.doi.org/10.1161/01.CIR.0000036014.90197.FA

[13] Kubica J, Sinkiewicz W. Diseases after myociardial infarction. Poland (Gdansk). VIA Medica, Publisher; 2008

[14] D'Amico M, Marfella R, Nappo F, Di Filippo C, De Angelis L, Berrino L et al. High glucose induces ventricular instability and increases vasomotor tone in rats. Diabetology. 2001; 44: 464-70. http://dx.doi.org/10.1007/s001250051644

[15] Erdmann E. Clinical Cardiology. The diseases of the heart, cardiovascular system and vessel. J. Drożdż. Poland (Lublin). Czelej Publisher; 2010.

[16] Stratton IM, Adler AI, Neil HA, Matthews DR, Manley SE, Cull CA et al. Association of glycaemia with macrovascular and microvascular complications of type 2 diabetes (UKPDS 35): prospective observational study. Br Med J. $2000 ; 321: 405-12$. http://dx.doi.org/10.1136/bmj.321.7258.405

[17] Sarnak MJ, Levey AS, Schoolwerth AC, Coresh J, Culleton B, Hamm LL et al. American Heart Association Councils on Kidney in Cardiovascular Disease, High Blood Presure Research, Clinical Cardiology, and Epidemiology and Prevention. Kidney disease as a risk factor for development of cardiovascular disease: A statement from the American Heart Association Councils on Kidney in Cardiovascular Disease, High Blood Pressure Research, Clinical Cardiology, and Epidemiology and Prevention. Circulation. 2003; 108: 2154-69. http://dx.doi.org/10.1161/01.CIR.0000095676.90936.80

[18] Gibson CM, Pinto DS, Murphy SA, Morrow DA, Hobbach HP, Wiviott SD et al. Association of creatinine and creatine clearance on presentation in acute myocardial infarction with subsequent mortality. J Am Coll Cardiol. 2003; 42: $1535-43$. http://dx.doi.org/10.1016/j.jacc.2003.06.001

[19] Sorensen CR, Brendorp B, Rask-Madsen C, Kober L, Kjoller E, Torp-Pedersen C. The prognostic importance of creatinine clearance after acute myocardial infarction. Eur Heart J. 2002; 23: 948-52. http://dx.doi.org/10.1053/euhj.2001.2989

[20] Most AS, Ruocco NA Jr, Gewirtz H. Effect of a reduction in blood viscosity on maximal myocardial oxygen delivery distal to a moderate coronary stenosis. Circulation. 1986; 74: 1085-92. http://dx.doi.org/10.1161/01.CIR.74.5.1085

[21] Joseph S. Alpert. Third Universal Definition of Myocardial Infarction. ESC Congress. 2012. 